
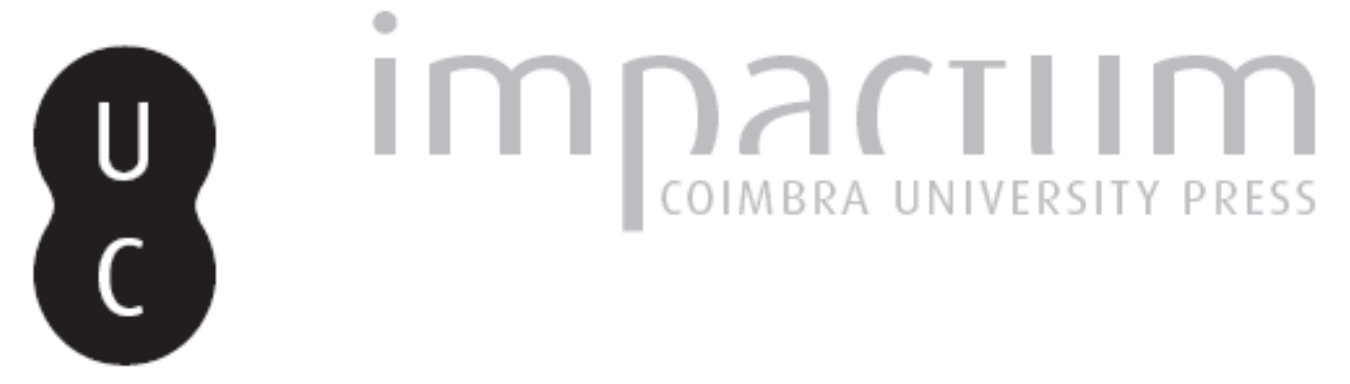

\title{
Ungaretti tradutor discreto e a analogia entre os poetas árcades Tomás António Gonzaga e Giovanni Meli
}

\author{
Autor(es): $\quad$ Covizzi, Lenira Marques; Wataghin, Lucia \\ Publicado por: Imprensa da Universidade de Coimbra \\ URL \\ persistente: \\ URI:http://hdl.handle.net/10316.2/42689 \\ DOI: \\ DOI:https://doi.org/10.14195/0870-8584_1_8
}

Accessed : $\quad$ 26-Apr-2023 15:53:07

A navegação consulta e descarregamento dos títulos inseridos nas Bibliotecas Digitais UC Digitalis, UC Pombalina e UC Impactum, pressupõem a aceitação plena e sem reservas dos Termos e Condições de Uso destas Bibliotecas Digitais, disponíveis em https://digitalis.uc.pt/pt-pt/termos.

Conforme exposto nos referidos Termos e Condições de Uso, o descarregamento de títulos de acesso restrito requer uma licença válida de autorização devendo o utilizador aceder ao(s) documento(s) a partir de um endereço de IP da instituição detentora da supramencionada licença.

Ao utilizador é apenas permitido o descarregamento para uso pessoal, pelo que o emprego do(s) título(s) descarregado(s) para outro fim, designadamente comercial, carece de autorização do respetivo autor ou editor da obra.

Na medida em que todas as obras da UC Digitalis se encontram protegidas pelo Código do Direito de Autor e Direitos Conexos e demais legislação aplicável, toda a cópia, parcial ou total, deste documento, nos casos em que é legalmente admitida, deverá conter ou fazer-se acompanhar por este aviso.

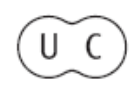




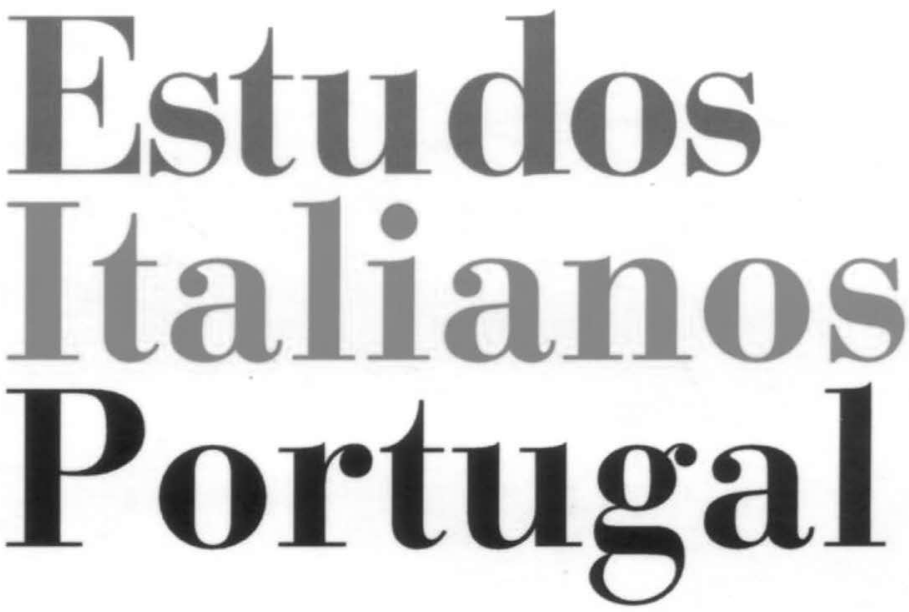

Instituto

Italiano

de Cultura

em Portugal

Nova Série

$\mathbf{N}^{\circ} \mathbf{1}$

2006 
UNGARETTI TRADUTOR DISCRETO E A

ANALOGIA ENTRE OS POETAS ÁRCADES

TOMÁS ANTÓNIO GONZAGA E GIOVANNI MELI

\section{Lenira Marques Covizzi \\ LuCia Wataghin}

É POSSÍvEL QUE NA POESIA ligada às arcádias italiana, brasileira e portuguesa haja uma tendência sistemática à fusão, em algum momento, do filão "culto" com o filão "popular". Sabe-se, por um lado, que da poesia arcádica portuguesa e brasileira surgiram modinhas brasileiras e que, vice-versa, há uma influência das modinhas bahianas na poesia do próprio Gonzaga $^{1}$. Quanto à situação italiana ${ }^{2}$, podemos pensar por exemplo na poesia de Giovanni Meli, que, por ser escrita no dialecto siciliano de um poeta culto, inscreve elementos e valores populares na tradição poética da elite e, viceversa, aproxima o público popular de um produto destinado ao público de elite ${ }^{3}$. Estas talvez sejam algumas das razões que

1 Braga, Th. Filinto Elysio e os dissidentes da Arcádia, apud Nepomuceno, L. A. A musa desnuda e o poeta tímido. O petrarquismo na arcádia brasileira. São Paulo, Patos de Minas: Annablume \& Unipam, 2002, p. 212.

2 A Accademia di Arcadia foi fundada em Roma em 1690 e difundiu-se, a partir deste ano, por toda a Itália; no século XVIII concentram-se os trabalhos dos poetas árcades, do célebre Pietro Metastasio aos menos famosos Giambattista Zappi, Faustina Maratti Zappi, Paolo Rolli, Ludovico Savioli Fontana, Jacopo Vittorelli, Giovanni Meli.

3 Sobre a fortuna popular de Meli ao longo dos séculos, v. Lorenzo Marinese, "Introduzione" a Giovanni Meli, Poesie. Milano: Mondadori, 1964, p. $13,14,31$. 
levaram Giuseppe Ungaretti ${ }^{4}$ a propor a analogia - o ponto de partida das presentes reflexões - entre T. A. Gonzaga e o poeta siciliano Giovanni Meli, membro das famosas Accademia del Buon Gusto e Galante Conversazione, ambas sediadas em Palermo. De facto, os árcades Tomás Antonio Gonzaga (1744-1810) e Giovanni Meli (1740-1815) são contemporâneos e pertencem a escolas poéticas irmãs (a Arcádia romana e as Arcádias brasileira e portuguesa): a afinidade que deriva destes factos é visível em suas poesias, apesar das distâncias geográficas e das circunstâncias muito diferentes que marcaram suas vidas. Gonzaga e Meli são cidadãos socialmente privilegiados (sobretudo Gonzaga) em seus respectivos ambientes. Mas, enquanto Giovanni Meli vive uma vida relativamente tranquila na Sicília - onde exerce a profissão de médico, primeiro, e depois de professor de química na Universidade de Palermo - o luso-brasileiro Gonzaga é um alto magistrado cuja vida é destruída brutalmente pela condenação ao desterro por causa da participação, nunca comprovada, na Inconfidência Mineira. Ambos compartilham princípios e ideais poéticos muito parecidos: amam cenários bucólicos, propondo o retorno à natureza e a uma vida mais natural e simples e, em termos de linguagem poética, à sobriedade e à racionalidade ${ }^{5}$, sendo fiéis ao petrarquismo e aos

${ }^{4}$ Ungaretti, G. Poesia III-IV. Milano: Mondadori, 1946, p. 218. Eis o trecho em que Ungaretti, antes de lançar a ideia da analogia entre T. A. Gonzaga e G. Meli, compara as situações italiana e brasileira: "Foi muito natural, portanto, que da poesia arcádica nascesse, a partir da canção de câmara, uma poesia popular entre as mais criativas [estrose]: a modinha brasileira. As situações se inverteram: entre nós, o popular era alcançado por meio de extremo artificio; lá, com extrema ingenuidade, imitando elegâncias consumadas."

5 Ideal da Arcádia é o "equilíbrio perfeito entre a razão e o sentimento, fórmula que $[. .$.$] se consagrou enquanto ideal de contenção de todo tipo de$ excesso, mesmo nos momentos de extrema dor e desespero", como bem sintetiza Jorge Ruedas de La Serna em Marilia de Dirceo, Brasil/México, Universidade de São Paulo/Editorial de la Universidad de São Paulo e Fondo de Cultura Económica (México), 2002. clássicos, de Anacreonte a Teócrito a Horácio a Virgílio, e contrapondo-se ao gosto dominante anterior, o barroco. Os cenários pastoris, habitados por Nises e Glaucestes, e o ideal de simplicidade e candor - presentes nas poéticas de todas as Arcádias - são a outra face de uma poesia estreitamente ligada a sociedades de cortes e salões, refinadas e sofisticadas, nas quais se cultivavam os sentimentos mais tenros e delicados e se estudavam as maneiras mais subtis e elaboradas para cortejar uma dama. De facto, ambos os poetas, Gonzaga e Meli, são mestres na poesia amorosa.

A força da poesia de Meli depende em grande parte da musicalidade e da vitalidade do dialecto siciliano, que vem, como escreve o maior crítico italiano do século XIX, Francesco De Sanctis, se contrapor à "exausta palavra italiana" e renovar, após séculos de desgaste, "uma velha literatura", imprimindo nela "o frescor da juventude" 6 . Por outro lado, lembra Ungaretti, "duas ilustres tradições líricas, a grega e a árabe" se encontram "com nova delicadeza" na poesia de Meli, cuja aparente simplicidade (conforme os ditames da Academia da Arcádia) é fruto de sofisticada elaboração. Vejamos por exemplo os dois quartetos citados por Ungaretti ${ }^{7}$ :

Dunca, Nici, nun Dunque Nice, non Logo, Nise, não durmiri dormire durmas

Spinsirata sutta l'ali Spensierata sotto Descuidada sob as l'ali asas

Di lu sonnu, chi Del sonno, che per Do sono, que por muriri poco pouco

Fa pri pocu li mur- non fa morire i Tira a vida dos mortali. mortali. tais.

${ }^{6}$ Francesco De Sanctis, "Discorso", in Giovanni Meli, Poesie siciliane. Roma: Avanzini e Torraca Editori, 1965, p. 46-47.

7 Ungaretti, G. Poesia III-IV, cit., p. 218. As nossas traduções para o italiano e o português têm função de simples auxílio à leitura. 
'Ntra li rosi e "ntra Fra le rose e fra i Entre as rosas e os li gigghi gigli lírios

Stai durmennu? Ah Stai dormendo? Estás dormindo? dun'accura

Chi'nzamai nun t'arrisbigghi Abbi cura!, Che se mai non ti Se tu não despertarisvegli

Langui tutta la na- Langue tutta la na- Desfalece a natutura. tura.

Em octossílabos ritmados, que revelam a força insuspeitada de palavras poéticas novas, de novos sons, o poeta descreve uma graciosa e simples cena pastoral, de gosto anacreôntico. Não há dúvida que tanta simplicidade é fruto de uma arte acabada (que deve muito à tradição anacreôntica) e do esforço de esconder a própria arte que a produziu; e é óbvio que o que importa, no ideal arcádico, não é ser natural, mas parecer natural ${ }^{8}$.

A ilusão (ainda que perfeita) de simplicidade, na poesia de Meli, não deve enganar o leitor. Sua poesia, académica

${ }^{8}$ Eis como Giacomo Leopardi (1798-1837), que admirava não só o poeta grego Anacreonte, mas também alguns árcades italianos, como Giovanni Meli e Giambattista Zappi, se aproxima de uma definição de simplicidade: "E assim quem sente e quer manifestar os impulsos do seu coração etc. a última coisa a que chega é a simplicidade e naturalidade, e a primeira coisa é o artifício e a afetação, e quem não estudou e não leu [...] não escreve certamente com simplicidade e naturalidade, porque se assim fosse, os melhores escritos seriam os das crianças: mas ao contrário neles não se vê outra coisa a não ser exagero e afetação e requinte - ainda que grosseiros - e aquela simplicidade não é simplicidade mas puerilidade: diz-se assim de algumas canções vulgares etc. etc., que por um lado são simples, mas comparem aquela simplicidade com a de Anacreonte, que parece ser o non plus ultra, e verão se é possível chamá-la simplicidade." Leopardi, G. Zibaldone di pensieri. v. I. Milano: Mondadori, 1937-1990, p. 24-25. Quanto à admiração de Leopardi pela tradição anacreôntica e pelos árcades italianos, ver Zibaldone di pensieri, cit., p. 31 e 35.

e cortesã, é destinada às academias da arcádia e aos salões da alta sociedade de sua época. É claro que nem mesmo o dialecto faz dela uma poesia de carácter popular. Quanto à questão da língua, é preciso notar a importância da inovação introduzida por Meli, um dos poucos autores a usar o dialecto como língua literária (Leopardi, em 1821, registrava9 só dois, entre eles, dignos de permanecer na história da literatura produzida na Itália: Meli e Goldoni).

É possível que Leopardi se tenha inspirado, em alguns aspectos, na poesia do siciliano; por exemplo, no título do poema leopardiano Il passero solitario talvez haja eco de um verso de Meli (Passari sulitarii, chi chianciti). Por outro lado, a ideia de que já exista em Meli algo de romântico talvez seja menos verdadeira. Mas é curioso terem sido apontadas marcas românticas tanto em Meli quanto em Gonzaga. Momigliano viu, na poesia de Meli, "prenúncios de sentimentos já românticos"; Cesareo e Natali reconhecem nele "antecipações do pessimismo leopardiano"10, teses pouco realistas, no caso do siciliano, pois sua poesia bucólica, harmoniosa, neoclássica, parece pertencer perfeitamente ao seu século. Apresentamos, em seguida, um soneto de Meli, acompanhado de nossas traduções auxiliares para o italiano e o português. O soneto, publicado com o título "Sonettu I" 11 , insere-se na tradição arcádica e petrarquista, seja pelo elogio da tranquilidade em meio à natureza, refúgio ideal do poeta e do sábio, seja pela forma perfeita dos hendecassílabos. Os vários aspectos da natureza atraem a delicada fantasia de Meli, contribuindo para aquele

\footnotetext{
${ }^{9}$ Leopardi, G. apud Marinese, L., "Introduzione”, cit., p. 23. Só em tempo recentes, mais de dois séculos depois do período em questão, os dialectos italianos se tornaram material linguístico de uso comum em poesia. Hoje, alguns dos melhores poetas italianos escrevem em dialecto.

${ }^{10}$ Cf. "Il 'buon gusto' in Sicilia: Giovanni Meli tra Arcadia e riformismo". In Savoca, G. Parini e la poesia arcadica. Roma: Laterza, 1996, p. 74.

${ }^{11}$ Poesie siciliane, 1787 (cerca).
} 
autoretrato do poeta - l'amicu di la paci e la quieti - que se revela só no último verso como objetivo e emblema de todo o poema.

Muntagnoli interrutti da vaddati;

Collinette interrotte da vallate;

Rocchi di lippu e areddara Rupi di muschio e edera vistuti;

Caduti d'acqui chiari inargintati;

vestite;

Vattali murmuranti e stagni muti;

Cascatelle d'acqua chiara argentata;

Ruscelli mormoranti e stagni muti;

Vausi e cunzarri scuri e imbuscati,

Balze e dirupi scuri e coperti di sterpi,

Sterili junchi e jinestri ciuruti; Sterili giunchi e ginestre fioTrunchi da lunghi età malis- rite; barrati,

Grutti e lambichi d'acqui già impitruti;

Passari sulitarii, chi chianciti;

Ecu, chi ascuti tuttu e poi ripeti;

Ulmi abbrazzati stritti da li viti;

Tronchi da lungo tempo mal ridotti,

Grotte e gocciolii d'acqua già impietriti;

Passeri solitari, che piangete;

Eco, che ascolti tutto e poi ripeti;

Olmi abbracciati stretti dalle viti;

Vapuri taciturni, umbri segreti,

Ritiri tranquillissimi, accugghiti

L'amicu di la paci e la quieti.
Vapori taciturni, ombre segrete,

Ritiri tranquillissimi, accogliete

L'amico della pace e della quiete.
Segue a nossa tradução para o português:

Colinas entrecortadas por vales;

Penhascos por musgo e hera vestidos;

Cascatas de clara água prateada;

Regatos murmurantes e charcos mudos;

Declives e escarpas escuros e cobertos de galhos,

Estéreis juncos e giestas floridas;

Troncos de há muito mal cuidados,

Grutas e pingos d'água já petrificados;

Pássaros solitários que chorais;

Eco que tudo escutas e repetes;

Olmos abraçados às videiras;

Vapores silenciosos, sombras secretas,

Refúgios tranquilíssimos, recebei

$\mathrm{O}$ amigo da paz e do sossego.

A vitalidade, a graça, a fantasia e a musicalidade que nos surpreendem nas éclogas, nos idílios, nos sonetos de Meli surgem de temas delicadíssimos, quase etéreos: pequenos quadros campestres, pequenas histórias de inspiração mitológica como a canzoncina "Lu labbru", em que o poeta aconselha a abelha a procurar o mel ["meli" em siciliano] nos lábios da sua amada, a pastora Nice. Note-se que o tema da abelha, tradicional na poesia amorosa desde Anacreonte, encontra-se também, com algumas variações, nas liras do luso-brasileiro Gonzaga. Desta pequena ode ${ }^{12}$, que foi tra-

12 Meli, G. "Lu labbru”. In Odi, com a tradução italiana de G. Santangelo. In Savoca, G. "Il 'buon gusto' in Sicilia...”, op. cit., p. 76-77. Note-se que a versão que apresentamos aqui não é completa. 
duzida para o alemão por Herder, oferecemos uma tradução auxiliar em português:

Dimmi, dimmi, apuzza nica: Unni vai cussì matinu?

Non c'è cima chi arrussica

Di lu munti a nui vicinu;

Trema ancora, ancora luci La ruggiada 'ntra li prati: Dun'accura nun ti arruci

L'ali d'oru dilicati!

Li ciuriddi durmigghiusi

'Ntra li virdi soi buttuni

Stannu ancora stritti e chiusi

$\mathrm{Cu}$ li testi a pinnuluni.

Ma l'aluzza s'affatica!

Ma tu voli e fai caminu!

Dimmi, dimmi, apuzza nica,

Unni vai cussì matinu?

Cerchi meli? E s'iddu è chissu,

Chiudi l'ali e 'un ti straccari; Ti lu 'nsignu un locu fissu,

Unni hai sempri chi sucari:

Lu conusci lu miu amuri,

Nici mia di l'occhi beddi?

'Ntra ddi labbra c'è un sapuri,

'Na ducizza chi mai speddi;
Dimmi, dimmi, apetta piccina:

Dove vai così mattino?

Non c'è cima che rosseggia

Del monte a noi vicino;

Trema ancora, ancora luce

La rugiada tra i prati:

Abbi cura a non bagnarti

L'ale d'oro delicate!

I fioretti sonnacchiosi

Ne'verdi lor bottoni

Stanno ancora stretti e chiusi

Con le teste penzoloni.

Ma l'aletta si affatica!

Ma tu voli e fai cammino!

Dimmi, dimmi, apetta

piccina,

Dove vai così mattino?

Cerchi miele? E s'egli è questo Chiudi l'ale e non stancarti

Te lo insegno un luogo fisso

Dove hai sempre che succhiare

Lo conosci il mio amore

Nice mia dagli occhi belli?

In quei labbri c'è un sapore,

Una dolcezza che mai finisce;
'Ntra lu labbru culuritu

Di lu caru amatu beni

C'è lu meli chiù squisitu:

Suca, sucalu, ca veni.
Nel labbro colorito

Del caro amato bene

C'è il miele più squisito

Succhia, succhialo, che viene.

Fala, fala, abelhinha,

Onde vais assim tão cedo?

Não há cume que enrubesça

Da montanha a nós vizinha;

Treme ainda, ainda brilha

O orvalho entre os prados: veja lá que não se molhem tuas douradas leves asas!

As florzinhas sonolentas

Em seus verdes botõezinhos

Ainda estão bem fechadas

Com as cabeças inclinadas.

Mas a azinha já se cansa!

Mas teu voo abre o caminho! Fala, fala, abelhinha,

Onde vais assim tão cedo?

Se é o mel que tu procuras

Fecha as asas, não te canses;

Eu te ensino um lugar certo

Onde há sempre o que sugar:

Tu conheces meu amor

Nise minha, olhos belos?

Nesses lábios há um sabor

há doçura inacabável; 
Em teus lábios coloridos Meu querido amado bem Há o mel mais saboroso Suga, suga que ele vem.

Apresentamos a seguir também duas quadras de outra canzoncina, L'occhi, que Goethe traduziu e inseriu em seu Sizilianisches Lied:

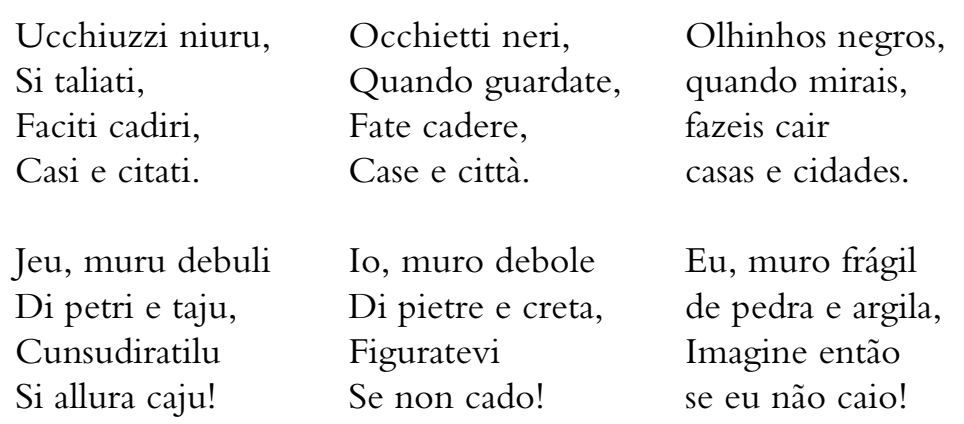

Os poemas sicilianos de Meli, além de serem traduzidos, no século XVIII, em várias línguas europeias (inglês, francês, alemão, finlandês), ganharam naturalmente também numerosas traduções para o italiano (a primeira saiu em 1893, assinada por outro célebre poeta, Ugo Foscolo) e até mesmo para o dialecto véneto ${ }^{13}$. Os versos de Meli, provavelmente em virtude de seus temas amorosos, da musicalidade e da (aparente) simplicidade, tiveram uma extraordinária difusão popular, sendo decorados e declamados, ainda em anos recentes, não somente nos bairros populares de Palermo, mas também nas comunidades de emigrantes italianos em Chicago e Nova Iorque ${ }^{14}$. Provavelmente pelas

${ }^{13}$ Sobre a fortuna crítica e as traduções da poesia siciliana de Meli ao longo dos século, cf. Marinese, L. op. cit., p. 28-30.

${ }^{14}$ V. Marinese, L. op. cit., p. 13, 14, 31. mesmas razões, os versos de Gonzaga também tiveram uma imensa fortuna popular, em Portugal e no Brasil ${ }^{15}$.

Quanto à relação de Ungaretti com a poesia arcádica no Brasil, é interessante saber, de início, que o seu encontro com Gonzaga deu-se provavelmente graças à leitura da Pequena história da literatura brasileira, de Ronald de Carvalho (F. Briquet \& C., Rio de Janeiro, 1935, 3. ${ }^{\text {a }}$ ed.), que o próprio Ungaretti cita como fonte das suas informações sobre outros assuntos referentes à história da literatura brasileira, numa nota às suas

15 Sobre a fortuna popular das liras de Gonzaga, ver: Eulálio, A. "Verso e reverso de Gonzaga" em Os melhores poemas de T. A. Gonzaga. São Paulo: Global, 1983; Cristóvão, F. Marília de Dirceu de T. A. Gonzaga, ou a poesia como imitação e pintura, Vila da Maia, Imprensa Nacional-Casa da Moeda, 1981, p. 35-37, e "Gonzaga, um cortesão burguês", em Nepomuceno, L. A. A musa desnuda e o poeta tímido, op. cit.

Terá sido Varnhagen (1816-1878) o primeiro estudioso de T.A. Gonzaga a dizer que nenhuma obra de poesia na língua portuguesa, afora Os Lusíadas, teve mais edições do que a lírica do poeta? Mais de dois séculos depois da primeira edição (1792, em Lisboa), a asserção se confirma: a recente tradução/edição mexicana da Marília de Dirceu regista, do século XVIII ao século XXI, 37 títulos, entre apenas algumas das mais importantes de suas diferenciadas edições, em Portugal e no Brasil. Quem sabe se esta quantidade de material e, porque não, eventuais outros a encontrar, estimula a realização de, também, edições genéticas? Elas poderão dar novo impulso à fortuna crítica do autor, colaborando para uma maior correção do trabalho hermenêutico. Fortuna crítica que também tem contado com estudos iluminadores destas liras: ver os recentes: Nepomuceno, L. A. A musa desnuda e o poeta tímido, op. cit. (sobre o petrarquismo na Arcádia brasileira, com um capítulo dedicado à poesia de Gonzaga); Cristóvão, F. Marília de Dirceu de T. A. Gonzaga, ou a poesia como imitação e pintura, op. cit., e o estudo introdutório à recente tradução para o espanhol de Jorge Ruedas de La Serna, em Marilia de Dirceo, op. cit. Além da sequência de antologias em edições paradidácticas, há também algumas liras de Gonzaga no: Cancioneiro de músicas populares no Portugal do XIX (César das Neves, Porto: Litografia Ocidental, 3 vols. 1893-8) e contamos, recentemente (1985 e 2001), com interpretações brasileiras de doze árias inspiradas nas liras de Gonzaga (CDs em primeira e segunda edições de Anna Maria Kieffer e Anna Maria Parsons). 
traduções ${ }^{16}$. A obra de Ronald de Carvalho serve de base ao trabalho de Ungaretti em muitos detalhes, além de determinar, provavelmente, a própria estrutura da secção de traduções brasileiras em "Poesia III-IV", secção que começa com mitos indígenas brasileiros, assim como a Pequena História cuida, no seu segundo capítulo, da poesia e das lendas populares no Brasil. Entre os detalhes que nos interessam aqui, o primeiro e fundamental é a escolha do poema a ser traduzido: precisamente a lira Tu não verás, Marília..., transcrita integralmente por Ronald de Carvalho em seu capítulo dedicado a T. A. Gonzaga. Ungaretti traduz também, em nota, alguns versos de Gonzaga citados no mesmo capítulo. Eis os versos: "Eu tenho um coração maior que o mundo" "17 [Posseggo un cuore grande più del mondo]; "O tempo, ó bela, que gasta/Os troncos, pedras e o cobre,/O véu rompe, com que encobre/À verdade a vil traição./Muda-se a sorte de tudo:/Só a minha sorte não?” [Cara, il tempo che consuma/Tronchi, sassi ed il serpente/Strapperà il velo che copre/La tradita verità?/Sorte è per tutti mutevole, /E per me non muterà?]. O curioso equívoco cobre/serpente, uma simples distracção, faz pensar em como, aos olhos de Ungaretti, a associação da poesia de Gonzaga com a natureza tropical (e talvez com os extravagantes precursores barrocos do luso-brasileiro) pode ter tornado plausível até a bizarra afirmação de que o tempo gasta troncos, pedras e cobras.

Convenções literárias são parte integrante da poesia de Gonzaga, como em geral de toda a poesia da Arcádia. No

16 Nota à tradução "A Santa Ines nella venuta della sua immagine”, de José de Anchieta, Poesia III-IV, op. cit., p. 214.

17 Note-se também que a estrofe "Eu tenho um coração maior que o mundo,/Tu, formosa Marília, bem o sabes:/Um coração, e basta,/Onde tu mesma cabes", assinalada por Ronald de Carvalho desde a primeira edição (1919) de sua Pequena História, foi modernamente recriada por Carlos Drummond de Andrade em mais de uma ocasião. Ver, por exemplo, em "Mundo grande" (Sentimento do mundo, 1935-1940): "Não, meu coração não é maior que o mundo./É muito menor./ Nêle não cabem nem as minhas dores." cancioneiro de Gonzaga, que se estrutura em grande parte numa série de convenções parecidas com aquelas da poesia de Meli (são os mesmos até os nomes de pastores e pastoras que povoam as campinas do luso-brasileiro e do siciliano), há porém uma série de poemas que se afasta dos temas bucólicos e cortesãos para tocar questões mais pessoais e dramáticas (o drama da separação de Marília, os sonhos de amor conjugal destruídos pela prisão e depois pelo exílio). É o caso da lira traduzida por Ungaretti, Tu não verás, Marília... ${ }^{18}$, na qual se inscrevem experiências e sonhos pessoais, temas e valores que se distanciam gradualmente da tradição petrarquista e também dos cenários bucólicos e da decoração alegórico/mitológica típica da poesia da Arcádia.

Trata-se de um poema muito apreciado por conter descrições, nos primeiros quatro quartetos, da paisagem mineira: são quadros quase realísticos, que apresentam cenas da mineração (a riqueza de Vila Rica), do desmatamento (necessário nesta fase da civilização dos "virgens matos", das "capoeiras inda novas"), do cultivo de outras riquezas americanas, o tabaco e a cana-de-açucar, com seus perfumes e sabores ("cheiroso fumo", "da doce cana o sumo"). A rica América que Marília não verá, conforme repete Dirceu, lhe é apresentada por intermédio da própria lira, como num espelho, que tem a função, por um lado, de proteger a mulher da visão directa da natureza selvagem e, por outro, de dar a palavra ao poeta. O poema é composto por quatro estrofes introduzidas pelo futuro negativo (Tu não verás, Marília), seguidas por três no

${ }^{18}$ A lira se encontra, com esta numeração, em: Obras Completas de Tomás António Gonzaga, edição crítica de Rodrigues Lapa. São Paulo, Rio de Janeiro, Recife, Porto Alegre: Companhia Editora Nacional, 1942, p. 156. O primeiro verso da lira é o famoso "Tu não verás, Marília, cem cativos", que Ungaretti utiliza, em forma abreviada, como título da sua tradução, "Tu non vedrai, Marilia...”. A tradução de Ungaretti foi publicada duas vezes: a primeira em Poesia III-IV, cit.; a segunda, em Il deserto e dopo, prose di viaggio e saggi. Milano: Mondadori, 1961. 
futuro afirmativo (Tu verás, Tu farás, Tu lerás) mais a estrofe conclusiva. Assim, são colocados em contraposição vários temas: o trabalho manual (na primeira parte) e o trabalho intelectual (na segunda); o estado de espírito da contemplação, que corresponde às descrições da primeira parte, e a reflexão, narração e até mesmo teatralização dos acontecimentos da segunda parte, em que se observa o casal no quadro familiar; o presente (a paisagem descrita) e o futuro (o ambiente doméstico sonhado). Há, ainda, a contraposição entre o novo e o velho: o novo, representado pela natureza americana selvagem, submetida aos esforços “civilizadores” dos colonos (desses esforços faz parte também provavelmente a própria poesia de Gonzaga, que impõe uma ordem e uma tradição na descrição dos novos ambientes) e o velho, representado não somente por toda a sofisticação da arte consumada do poeta, mas também por temas tipicamente clássicos, que emergem na segunda parte, como o carpe diem e a afirmação da mediocridade enquanto melhor condição para o homem. Por fim ${ }^{19}$, há o ambiente exterior com sua dureza (e variedade), que é explicitamente negado, em favor do espaço interno da paz doméstica e da tranquilidade dos estudos. A brilhante construção simétrica do poema (com as fortes anáforas da primeira parte, que se dissolvem gradualmente na segunda) faz pensar num espelho colocado estrategicamente num lugar do qual, dependendo do ponto de vista, vê-se um lado ou outro da contraposição: a natureza que está fora da janela, ou o am-

19 Há mais uma contraposição que não está explicitada no poema, mas é um sinal importante do valor de ruptura da poesia de Gonzaga em relação à tradição: trata-se da contraposição entre o tema proposto da felicidade doméstica, do amor entre os cônjuges, e o tema do amante infeliz, eterna e irremediavelmente distante da mulher amada. Os quadros da felicidade que advêm do amor correspondido são novidade na tradição petrarquista (à qual Gonzaga ainda pertence), sendo que o petrarquismo, por definição, canta amores não retribuídos e certamente não sonhos de felicidade burguesa e tranquilidade emocional. Ver Nepomuceno, L. A. "Gonzaga, um cortesão burguês", op. cit. biente interno, protegido, de um escritório numa tranquila morada. Ungaretti descreve assim a cena, observando a desproporção vertiginosa entre a visão da natureza e a do interior da cena doméstica, provocada pela construção do poema: "[...] o poeta escuta, consultando documentos cansativos, a musa tranquila sentada ao seu lado na intimidade de um cômodo: enquanto irrompe da janela, que como um precioso espelho veneziano é luxuosamente contida em uma enlouquecida moldura rococó, permanecendo remotíssima, a visão de uma natureza selvagem" 20 .

A moldura rococó está "enlouquecida", diz Ungaretti; os delicados ornamentos, os detalhados e fantasiosos quadrinhos, que se organizam quase que visualmente compondo arabescos em tantos outros poemas árcades, adquirem aqui uma função que vai muito além da pura decoração, colocando-se em relação viva e problemática com os temas propostos no poema.

O verbo "ver", conjugado na segunda pessoa do futuro indicativo, é recorrente nas liras de Gonzaga, quase a sublinhar o carácter em grande parte visual de sua poesia (conforme a poética neoclássica, que interpreta a teoria horaciana do paralelismo entre as artes - ut pictura poesis - como um convite a poetar como se pinta ${ }^{21}$ ) e, por outro lado, a curiosa colocação no futuro dos pensamentos e dos sonhos do poeta, constantemente distanciado da realidade presente. Vejamos por exemplo na lira $\mathrm{XII}^{22}$ (p. 106):

Quando à janela saíres,

Sem quereres descuidada,

Tu verás, Marília, a minha

E minha pobre morada

${ }^{20}$ Poesia III-IV, cit., p. 219.

${ }^{21}$ Ver Cristóvão, F. "Ut pictura poesis?” In Marília de Dirceu de T. A. Gonzaga ou a poesia como imitação e pintura, cit.

22 Gonzaga, T. A., Marília de Dirceu. Porto Alegre: L \& PM, 2000, p. 107. 
É retomada a convenção pastoral: os dois pastores apaixonados, Dirceu e Marília, estão separados porque Dirceu já perdeu a liberdade; o verás tem função dramática, porque pela janela, desta vez aberta, Marília verá a janela e a modesta casa onde Dirceu não está mais. O leitor fica admirado e surpreso com os detalhes: as duas janelas (a segunda, substituída por um pronome), o curioso efeito obtido pela repetição da palavra minha, o futuro verbal que se alia instantaneamente ao passado (porque o ver significa automaticamente lembrar, para a solitária Marília).

Efeitos decorativos se encontram também na lira VII ${ }^{23}$ (III parte), que narra o sonho de Dirceu, ainda livre, de se casar com Marília e levá-la consigo para Portugal. Em toda a lira recorre o característico verás gonzaguiano com que Dirceu apresenta a Marília, misturadas a referências mitológicas, as imagens poderosas e fantásticas desta viagem por mar. Vejamos, por exemplo, a quarta estrofe, em que recorre também, novamente, a imagem da janela, desta vez dourada, através da qual Marília verá o mar:

Verás como o Leão, na proa arfando,

Converte em branca espuma as negras ondas,

$\mathrm{E}$ as talha e corta com murmúrio brando;

Verás, verás, Marília,

Da janela dourada,

Que uma comprida estrada representa

A linfa cristalina, que, pisada

Pela popa que foge,

Em borbotões rebenta.

A repetição do verás reforça a energia contida neste convite a imaginar a maravilhosa viagem, no final da qual a brasileira Marília chegará finalmente aos "saudosos lares” [por-

${ }^{23}$ Ibidem, p. 178. tugueses] de Dirceu, onde será saudada pelo Tejo, que “dará no leme do baixel um beijo". A lira termina com uma orgulhosa comparação, feita por Dirceu, entre a autêntica riqueza (Marília) que está levando a Portugal, e as "pedras de valor" e os "montes de ouro" de Vila Rica. Já estão presentes nesta lira, ainda que com função menos dramática do que na fase da prisão e do degredo, os temas das relações entre colónia e metrópole, entre natureza e civilização, entre pátria e exílio. São temas (os mesmos que estão presentes na lira Tu não verás, Marília...) com certeza profundamente interessantes para Ungaretti, que, como Gonzaga, vive a sorte do "exilado" (ou melhor, do emigrante) desde o dia em que nasceu, não na Itália, terra dos seus antepassados, mas no Egipto, onde o pai encontrara um emprego como operário nas obras de construção do Canal de Suez.

As traduções E. de Monglave e P. Chalas ${ }^{24}$, tradutores de Tu não verás, Marília... para prosa francesa (1825), lamentam, no pequeno prefácio que precede a tradução, "le peu de flexibilité de la prose française", que limitou suas possibilidades de reproduzir a harmonia, o ritmo, o estilo

${ }^{24}$ Monglave E. de \& Chalas, P. Marilie. Chants Élégiaques de Gonzaga, traduits du portugais. Paris: Panckoucke, 1825. A tradução para o italiano, de Giovenale Vegezzi-Ruscalla, é intitulada Marilia di Dirceo, e foi publicada em 1844, em Turim, pela Stamperia Sociale degli Artisti. Além dessas, existem as seguintes traduções: para o latim, pelo Dr. A. Castro Lopes, Algumas Lyras Escolhidas de Marília de Dirceu traduzidas para verso latino. Amaryllidos Dircaei Aliquot Lyrica Selecta. Rio de Janeiro: Quirini \& Fratis, 1868, e Rio de Janeiro: Tipografia de Leuzingerius et Filii, ed. correcta e augmentada, 1887 (tradução em uso nas escolas do Império); e para o espanhol, Marilia de Dirceo, trad. de Jorge Ruedas de la Serna, op. cit. Boris Schnaiderman dedica alguns artigos à tradução para o russo da lira LXXI de Gonzaga (a numeração corresponde à edição crítica de Rodrigues Lapa, 1957). O primeiro saiu no Suplemento Literário de O Estado de S. Paulo de 16/06/1962, e foi retomado, com alguns acréscimos, no n. ${ }^{\circ} 1$ da revista Tradterm, Universidade de São Paulo, 1994 e em Fortaleza Voadora (Fortaleza, s/d); ainda, com o título "Púchkin e Gonzaga. Da sanfoninha ao violão", na Revista USP n. 45, março-abril-maio 2000, p. 82-84. 
do poema de partida. Esta tradução parece quase uma caricatura do velho estilo (não só francês) inspirado na ideia da tradução como belle infidèle. Com uma peculiaridade: tudo, nela, é sistematicamente aumentado, exagerado, potenciado, quando não é simplesmente acrescentado di sana pianta. O simples "cascalho" de Gonzaga torna-se l'épais gravier qui cache l'or aux cupides humains; "No fundo da bateia": au fond du vase que ses mains agitent; Marília não verá "queimar as capoeiras", mas la flamme dévorer les jeunes taillis; a "espaçosa mesa" será une immense table; "os grandes livros": énormes volumes, "decidir os pleitos": juger des graves contestations; "Lendo os fastos da sábia, mestra História/Os cantos da Poesia": Tu me réciteras les plus beaux vers de nos poètes; tu me rediras les plus sages leçons de l'histoire. O gosto pelo hiperbólico estende-se quase a tudo e custa acreditar que a língua francesa não permita maior sobriedade. Sem falar na "francesização" e na actualização, digamos, à época dos tradutores, produzidas pelo recurso a expressões quase estereotipadas, como je poursuivrai mon pénible labeur avec plus de courage, que traduz o "Gostoso tornarei a ler de novo/O cansado processo."

Monglave e Chalas acrescentam também um detalhe (o adjectivo chère, em italiano cara, que precede o nome de Marília na tradução) que será retomado (ou talvez instintivamente reescolhido) por Giovenale Vegezzi-Ruscalla, que traduz a lira pela primeira vez para o italiano, em 1844, e por Ungaretti, que a traduzirá em 1946. As estrofes descritivas são talvez as que ganharam as melhores traduções. Vejamos as primeiras duas:

Tu não verás, Marília, cem cativos Tirarem o cascalho e a rica terra,

Ou dos cercos dos rios caudalosos,

Ou da minada Serra.
Não verás separar ao hábil negro

Do pesado esmeril a grossa areia,

E já brilharem os granetes de oiro

No fundo da batéia.

A tradução de Ungaretti, naturalmente musical, é de sabor hermético, pelas dificuldades de compreensão criadas por algumas escolhas: por exemplo, o verbo "sollevare" para traduzir "tirarem" ou a manutenção do termo "bateia" (que será explicado em nota). A modernidade desta tradução, muito agradável não só pela harmonia rítmica e pela sonoridade, mas também pela precisão (que pressupõe o mais cuidadoso respeito pelo texto gonzaguiano), está talvez exactamente na tranquilidade e sobriedade com que essa precisão se manifesta:

Tu non vedrai, Marilia, cento schiavi

Pietrisco e terra ricca sollevare

Da cinte zone di copiosi fiumi

E da minati monti.

Non vedrai il destro Nero separare

Il pesante smeriglio dalla sabbia

$\mathrm{E}$ in fondo alla bateia suscitare

Brillanti grani d'oro.

A tradução de Vegezzi-Ruscalla, com seus versos precisos parcialmente rimados, imagens imediatas e grande clareza na descrição, também é agradável e musical:

Tu non vedrai, mio ben, gli schiavi estraggere

I minerali più preziosi e conti

O dalle sponde di torrenti rapidi

$\mathrm{O}$ da scavati monti. 
Tu non vedrai dall'abil Nero scernere

Lo smeriglio pesante dall'arena

Grossa, e la conca di pagliuole aurifere

Splender ripiena.

As soluções de Ruscalla (cuja tradução é transcrita integralmente por Ungaretti na primeira nota à sua própria tradução da lira) são em geral delicadas e sóbrias, apesar do peso que lhes é conferido, aos nossos olhos, pela linguagem oitocentista, romântica e talvez até marcada por um certo patriotismo (é a época em que se prepara o Risorgimento italiano e Turim, a cidade de Ruscalla, é um dos focos do movimento). Vejamos por exemplo a estrofe:

Lerás em voz alta a imagem bela;

Eu, vendo que lhe dás o justo apreço,

Gostoso tornarei a ler de novo

O cansado processo.

A estrofe é problemática, pela pouca clareza da expressão “a imagem bela"; tanto que Rodrigues Lapa, um dos mais estimados conhecedores da obra de Gonzaga, julga que se trataria de uma construção afrancesada, que indicaria não o objecto do acto da leitura, mas a própria Marília. Ou seja, a expressão "a imagem bela" significaria "com belo gesto, com a figura bela". Naturalmente, em sua edição da Marília de Dirceu, Rodrigues Lapa coloca uma vírgula antes da expressão. Nenhum dos tradutores (nem os franceses) interpretou o verso assim. Vegezzi-Ruscalla, que deve ter sido um bom romântico, aproveitou a ocasião para aludir a alguma acção heróica e traduziu com muita fantasia, mas também com uma certa vivacidade:

Ed io incontrando una azion magnanima

Fatta più viva su' tuoi labbri, o amica,

Disacerbata delle mie vigilie

Sarà la ria fatica.
A estrofe é dificil, talvez por excesso de simplicidade. E há, também, duas pouco aprazíveis interrupções do ritmo por incisos, além de uma redundância da qual não se entende facilmente a razão [tornarei a ler de novo/o cansado processo]: difícil, para o tradutor, resistir à tentação de enfeitá-la um pouco. A simplicidade - princípio e ideal da Arcádia - é fruto de meditada elaboração; é uma escolha. Mas é preciso ser um tradutor discreto, como Ungaretti, para traduzir com simplicidade equivalente:

All'immagine bella alzerai il tono,

E nel vederle reso il giusto omaggio

Tornerò lieto nuovamente a scorrere

Il noioso processo. 